\title{
Influência da estratificação térmica no volume útil e no comportamento hidrodinâmico de lagoa de estabilização: determinação experimental e teórica
}

\author{
Influence of thermal stratification in useful volume and in hydrodinamic \\ behavior of stabilization pond: theoretical and experimental evaluation
}

\begin{abstract}
Erich Kellner
Doutor em Engenharia Civil na área de Hidráulica e Saneamento pela Escola de Engenharia de São Carlos da Universidade de São Paulo (EESC/USP). Professor adjunto da Universidade Federal do ABC (UFABC)
\end{abstract}

\author{
João Fernandes Viana Moreira \\ Doutor em Engenharia Civil na área de Hidráulica e Saneamento pela EESC/USP. Pós-doutorando da Université de Sherbrooke \\ Eduardo Cleto Pires \\ Livre-docente em Engenharia Civil na área de Hidráulica e Saneamento pela EESC/USP. Professor titular da EESC/USP
}

\begin{abstract}
Resumo
Lagoas de estabilização localizadas em regiões com variações elevadas de temperatura ao longo do dia tendem a apresentar estratificação térmica, um fenômeno que altera o volume útil da lagoa. Neste trabalho, apresentam-se resultados experimentais obtidos em duas lagoas, facultativa e maturação, construídas na região central do estado de São Paulo. O acompanhamento do perfil de temperatura mostrou a ocorrência de estratificação térmica com ciclo nictimeral nas duas lagoas. Os ensaios hidrodinâmicos indicaram comportamento semelhante ao de reatores com mistura completa, com zonas mortas, volume útil de aproximadamente $60 \%$ na lagoa facultativa e 30\% na lagoa de maturação. Os experimentos corroboraram os resultados teóricos obtidos com o modelo matemático para previsão da estratificação térmica.
\end{abstract}

Palavras-chave: lagoa de estabilização; estratificação térmica; ensaio hidrodinâmico; rodamina B; acúmulo de lodo; volume útil.

\begin{abstract}
Stabilization ponds located in places that present high temperature variations along the day have a tendency to present thermal stratification, a phenomenon that changes the useful volume of the pond. This paper presents experimental results from two stabilization ponds, facultative and maturation, built in the central area of the state of São Paulo, Brazil. The observation of the temperature profile showed the occurrence of thermal stratification with the nictimeral cycle in both ponds. Hydrodynamic tests showed a pattern that resembles the behavior of complete mixing reactors with dead zones, resulting in useful volumes close to $60 \%$ for the facultative pond and $30 \%$ for the maturation pond. The experiments confirm the theoretical results obtained based on a mathematical model to predict thermal stratification.
\end{abstract}

Keywords: stabilization ponds; thermal stratification; hydrodynamic test; rhodamine B; sludge accumulation; useful volume.

\section{Introdução}

A eficiência do tratamento nas lagoas de estabilização é função do transporte hidráulico assim como dos processos químicos e biológicos que ocorrem em seu interior. Autores como Chu e Soong (1997), por exemplo, mostram que esses processos são influenciados pela estratificação térmica e pela geometria das lagoas.

Devido à diferença de temperatura ou salinidade entre as camadas líquidas das lagoas, as camadas mais leves tendem a se sobrepor às mais densas criando condição de estratificação. Essa estratificação pode ser quebrada pelo vento que sopra sobre a superfície da água. As camadas superficiais do corpo d'água são misturadas graças aos efeitos cisalhante e de mergulho que o vento exerce sobre o líquido e, no decorrer do tempo, as camadas mais densas e menos turbulentas misturam-se às menos densas (CHU; SOONG, 1997).

Nas lagoas de estabilização, a zona afetada pelas correntes de circulação depende da estabilidade da estratificação, da magnitude da vazão e da geometria da lagoa. 
Em lagoas completamente misturadas, o fluxo que se encaminha para a saída é radial, tomando água, igualmente, de todas as direções. No entanto, em lagoas estratificadas, como os dispositivos de saída localizam-se na região do epilímnio e, por serem as vazões efluentes pequenas em relação ao volume total da lagoa, o fluxo vem apenas dessa zona. Portanto, a região de tomada de água é aquela determinada pelo volume útil da lagoa, com influência direta sobre o tempo de detenção hidráulica (TDH) da lagoa e a ocorrência de curtos-circuitos.

Segundo Teixeira (1995) e Thackston, Shields Junior e Schroeder (1987), o termo curto-circuito não tem uma definição técnica precisa, mas é geralmente usado para descrever situações nas quais os caminhos percorridos por partículas do líquido resultam em tempos de residência na lagoa (ou no reator) inferiores ao TDH teórico.

No interior das lagoas de estabilização, assim como em outros reatores, pode ocorrer a formação de três regiões distintas entre si, denominadas: zona advectiva, zona morta e zona de mistura. A principal diferença entre a zona morta e a zona de mistura, é a velocidade de troca do líquido entre a referida zona e a zona advectiva. A zona morta apresenta uma taxa de troca muito menor quando comparada à região de mistura. As zonas mortas não fazem parte do volume pelo qual o líquido escoa; dessa maneira, o volume efetivo da lagoa é menor que o volume total e o TDH real é menor que o TDH teórico, ocorrendo então os chamados curtos-circuitos. As zonas mortas podem ser formadas por material sedimentado no fundo da lagoa, desenvolvendo bancos de lodo, e por regiões da massa líquida, principalmente do hipolímnio, quando estagnadas devido à ocorrência de estratificação térmica duradoura. Dessa maneira há, do ponto de vista térmico, um volume útil formado principalmente por uma zona advectiva e uma zona de mistura, que deve influenciar o TDH da lagoa ao longo do dia.

O objetivo deste trabalho foi analisar teórica e experimentalmente a interferência da estratificação térmica no volume útil e na distribuição da massa de Rodamina no interior de lagoas de estabilização localizada na região sudoeste do estado de São Paulo, bem como no comportamento hidrodinâmico dessas unidades.

\section{Material e métodos}

\section{Caracterização do local da pesquisa}

A Estação de Tratamento de Esgoto (ETE) que serviu de base para a condução dos experimentos localiza-se no município de Novo

Tabela 1 - Dimensões básicas características das lagoas de estabilização de Novo Horizonte

\begin{tabular}{lcccc} 
& Unidade & LA & LF & LM \\
Área média & ha & 0,5700 & 3,2689 & 1,8287 \\
Profundidade & $\mathrm{m}$ & 3,50 & 1,80 & 1,82 \\
Volume & $\mathrm{m}^{3}$ & $19.950,00$ & 58.533 & 33.234 \\
\hline
\end{tabular}

Fonte: adaptado de Moreira (2006)

ha: hectare; LA: lagoa anaeróbia; LF: lagoa facultativa; LM: lagoa de maturação.
Horizonte, no Estado de São Paulo, latitude 21²8’28” Sul, longitude 49¹3'17" Oeste, a 447m acima do nível do mar.

A referida ETE, foi projetada para vazão média de 46,5 L/s e é operada pela Companhia de Saneamento Básico do Estado de São Paulo (Sabesp), desde fevereiro de 1999, quando iniciou suas atividades. Constituída por lagoas de estabilização dispostas segundo o tradicional sistema australiano, a estação é composta por tratamento preliminar (gradeamento fino, caixa de areia e medidor de vazão), seguida de uma lagoa anaeróbia, uma lagoa facultativa e uma lagoa de maturação dispostas em série.

Os efluentes da lagoa anaeróbia eram reunidos em uma caixa de passagem e, em seguida, distribuídos para quatro pontos localizados na entrada da lagoa facultativa, distanciados $27 \mathrm{~m}$ entre si, tangenciando a lâmina líquida da lagoa. Os dispositivos de saída da lagoa facultativa eram constituídos por quatro tubulações distanciadas $27 \mathrm{~m}$ entre si e localizadas próximas à superfície líquida. Os efluentes da lagoa facultativa eram, então, reunidos em uma caixa de passagem e distribuídos em três pontos, ao longo da largura da lagoa de maturação, em tubulações que tangenciavam a lâmina líquida da lagoa, distanciadas $30 \mathrm{~m}$ entre si. Os dispositivos de saída da lagoa de maturação eram semelhantes àqueles da lagoa facultativa, mas eram três, espaçados $30 \mathrm{~m}$ entre si ao longo da largura da lagoa.

A Tabela 1 apresenta as dimensões básicas das lagoas de estabilização que compõem a ETE de Novo Horizonte.

\section{Batimetria}

Antes dos ensaios hidrodinâmicos realizados nas lagoas facultativa e de maturação, procedeu-se à batimetria dessas unidades com o objetivo de medir a camada de lodo presente. As medidas foram efetuadas em agosto de 2004.

O equipamento utilizado para a realização da batimetria era composto por uma haste feita com tubo de PVC, tendo uma placa circular com diâmetro de $30 \mathrm{~cm}$ em uma das extremidades, e uma haste de cobre, com escala métrica, de diâmetro inferior ao da haste de PVC, conforme citado por Gonçalves (2000).

Ao longo do comprimento da lagoa facultativa, em ambos os lados, foram colocadas estacas a cada $5 \mathrm{~m}$, definindo-se 70 seções de medição. Uma corda presa a duas estacas opostas serviu de guia para a medição da altura da camada de lodo. Com auxílio de um barco e de réguas milimetradas mergulhadas a cada $5 \mathrm{~m}$ ao longo da corda guia, fizeram-se as leituras da camada de lodo em relação ao fundo da lagoa e ao nível d'água. A haste de PVC foi utilizada para determinar a profundidade da interface sólido-líquido, onde repousava devido ao assentamento da placa circular sobre a fase sólida. Após a localização da camada de lodo, introduziu-se a haste de cobre com escala métrica pelo interior da haste de PVC, detendo-se ao encontrar o fundo da lagoa, conforme descrito por Gonçalves (2000). A batimetria da lagoa de maturação teve procedimento 
semelhante, mas, devido à sua forma regular, utilizou-se espaçamento de 10 m entre os pontos de medição ao longo de cada seção, separadas entre si pelos mesmos $5 \mathrm{~m}$.

Os dados referentes à altura da camada de lodo foram lançados em no programa gráfico Surfer v. 8, que permitiu a estimativa do volume de lodo de cada uma das lagoas, bem como o volume real de cada uma delas.

\section{Pontos de medição e coleta de amostras}

A Figura 1 mostra esquematicamente os pontos de medição e a coleta de amostras.

Para os ensaios hidrodinâmicos realizados na lagoa facultativa (LF), o traçador foi introduzido no ponto P1 (caixa de passagem) e as amostras para construção das curvas de saída foram coletadas no ponto I. Nesse período, no ponto $\mathrm{O} 1$, foram realizadas medidas de temperatura ao longo da profundidade da lagoa, bem como coletadas amostras do líquido da lagoa junto à superfície, a 0,75 e 1,50 m de profundidade. Os ensaios hidrodinâmicos na lagoa de maturação (LM) seguiram o mesmo procedimento, agora com introdução do traçador em P2 (caixa de passagem) e amostragem em II e O2.

\section{Determinação dos perfis verticais de temperatura}

Para avaliar a estratificação térmica, durante os ensaios hidrodinâmicos, submergiu-se, no centro de cada lagoa, uma haste contendo sensores para medição da temperatura ao longo da profundidade. A referida haste possuía altura de $1,80 \mathrm{~m}$, com sensores fixos a ela e distanciados $15 \mathrm{~cm}$ entre si, sendo o primeiro deles instalado acima do nível d'água e os demais, submersos.

Os sensores foram interligados a um data logger, construído no Departamento de Hidráulica e Saneamento da Escola de Engenharia de São Carlos (EESC), com capacidade para armazenar até 215 dados, ou 19 perfis de temperatura. Em intervalos predeterminados, os dados eram descarregados em um microcomputador com auxílio de um programa computacional e armazenados em formato adequado para as manipulações posteriores.

\section{Ensaio hidrodinâmico}

Realizaram-se quatro ensaios hidrodinâmicos, sendo dois na lagoa facultativa e dois na lagoa de maturação. A fim de avaliar os efeitos climáticos e suas interferências na resposta ao ensaio hidrodinâmico, conduziu-se o experimento em duas épocas distintas, uma caracterizando o período de verão e outra, o período de inverno. O traçador era introduzido na caixa de distribuição de vazão que antecede as lagoas facultativa e de maturação.

Para esses ensaios, foi utilizada a técnica com injeção instantânea, na qual o traçador deve ser lançado rapidamente na vazão

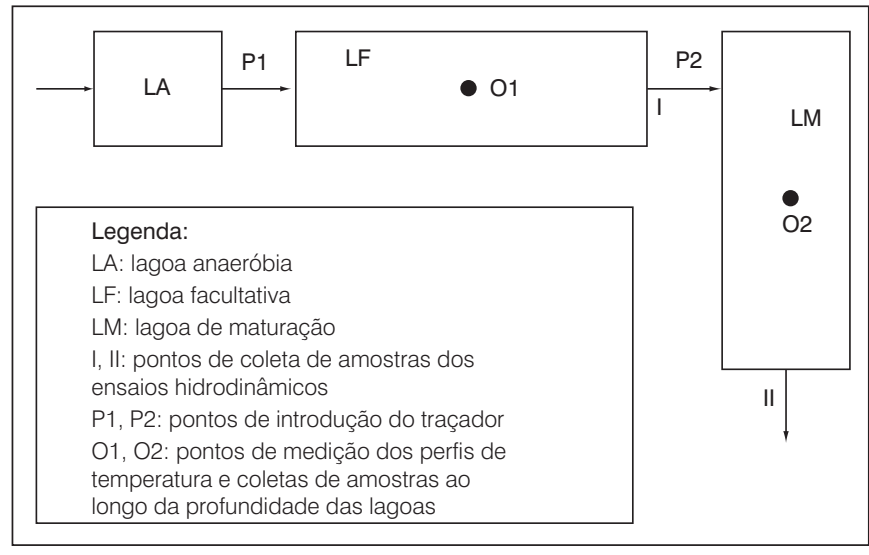

Figura 1 - Pontos de coleta e amostragem empregados na ETE de Novo Horizonte

afluente em um pulso único, conforme proposto por Levenspiel (1974). Como traçador, empregou-se a Rodamina B $\left(\mathrm{C}_{28} \mathrm{H}_{31} \mathrm{~N}_{2} \mathrm{O}_{3} \mathrm{C}_{1}\right)$, CAS no 81-88-9.

\section{Coleta de amostras e determinação da concentração de Rodamina B}

No primeiro ensaio realizado na lagoa facultativa, a amostragem do efluente foi feita manualmente. Durante 20 dias, a cada seis horas, um volume de 1 L era coletado do efluente. Para o segundo ensaio, o procedimento de amostragem, que durou 31 dias, foi automatizado, com um amostrador da marca ISCO. Foram coletadas amostras de $1 \mathrm{~L}$ em intervalos que variaram de uma hora, no início de cada ensaio, até seis horas durante a última semana do ensaio.

Durante o segundo, terceiro e quarto ensaios hidrodinâmicos, com auxílio de um barco, foram coletadas amostras do líquido no interior das lagoas facultativa e de maturação, próximo à haste que continha os sensores para medição de temperatura, a fim de se avaliar a distribuição da concentração do traçador ao longo da profundidade da lagoa e analisá-la juntamente com os perfis térmicos. Em cada amostragem, foram coletadas amostras a $5 \mathrm{~cm}, 70 \mathrm{~cm}$ e $150 \mathrm{~cm}$ abaixo do nível d'água nos mesmos horários em que ocorriam os registros automáticos dos perfis de temperatura. Para cada uma dessas amostras, determinou-se a concentração de Rodamina B, sendo seus valores lançados em gráficos ao longo da profundidade e comparados ao comportamento dos perfis térmicos correspondentes.

Para se medir a concentração de Rodamina B, as amostras foram inicialmente centrifugadas, conforme proposto por Cossio (1993) para eliminar os sólidos suspensos, constituídos principalmente por algas. A fluorescência das amostras foi medida em fluorômetro da marca Turner Quantech, modelo FM 109525, e a concentração, determinada por meio de uma curva de calibração.

O percentual de recuperação da massa do traçador foi calculado empregando-se a Equação 1. 
$\begin{aligned} & \% \text { de Recuperação } \\ & \text { do traçador }\end{aligned}=\frac{\sum_{i=2}^{n}\left(\frac{C_{i}+C_{i-1}}{2}\right) \cdot\left(t_{i}-t_{i-1}\right) \cdot Q_{e}}{M_{0} \cdot 0,01}$

Equação 1

onde:

$C_{i:}$ concentração $(\mu \mathrm{g} / \mathrm{L})$ do traçador no tempo $t_{i}(\mathrm{~h})$;

$Q_{e}$ : vazão efluente $\left(\mathrm{m}^{3} / \mathrm{h}\right)$;

$M_{0}$ : a massa de traçador injetada na lagoa ( $\left.\mu \mathrm{g} /\right)$;

0,01: fator percentual.

Segundo Cossio (1993), é necessário chegar a 85\% de recuperação da massa de corante para validar o experimento; a partir do segundo experimento, o porcentual de recuperação era avaliado continuamente e utilizado, em conjunto com o tempo de detenção hidráulica teórico, como um dos critérios para interrupção dos ensaios hidrodinâmicos.

\section{Análise qualitativa do modelo de escoamento}

A análise qualitativa do escoamento foi feita a partir dos gráficos com os valores adimensionais de $C / C_{0}$ em função de $t / t_{m}$, onde $C$ é a concentração do traçador na saída das lagoas em função do tempo, $C_{0}$ é a concentração do traçador injetado na lagoa, obtido a partir da massa do traçador dividido pelo volume útil da lagoa; té o tempo de decorrência do experimento e $t_{m}$ é o TDH teórico.

A curva de distribuição do tempo de residência é obtida experimentalmente ao se fornecer, à entrada da corrente fluida, um sinal em forma de pulso de um traçador e se medir sua concentração na saída do recipiente ao longo do tempo $t$.

Levenspiel (1974) propôs as Equações 2 e 3 que representam, respectivamente, a variância e a média dessa família de curvas:

$\sigma_{t}^{2}=\frac{\delta^{2}}{t_{m}^{2}}=2 \cdot d-2 \cdot d^{2} \cdot\left(1-e^{\frac{-1}{d}}\right)$

Equação 2

$\bar{\theta}=\frac{t^{2}}{t_{m}^{2}}$

Equação 3

\section{Simulação numérica do volume útil das lagoas}

A partir dos valores médios mensais de precipitação, temperatura do ar e vazão média afluente, empregou-se o modelo matemático proposto por Kellner (2000) para cálculo do volume útil da lagoa de estabilização resultante da ocorrência da estratificação térmica.

Os perfis verticais horários de temperatura foram calculados para o período amostral, sendo empregado o método numérico de RungeKutta de $4^{a}$ ordem para resolução das equações que descrevem a transferência de calor entre as camadas líquidas. Com o perfil de temperatura, determinou-se o perfil de densidade da água na lagoa. De acordo com o proposto por Esteves (1998), para identificação da ocorrência do fenômeno de estratificação térmica considerou-se que esse fenômeno ocorre toda vez que a diferença de temperatura entre duas camadas provoca diferença de densidade do meio líquido igual ou superior àquela observada para as temperaturas de 4 e $5^{\circ} \mathrm{C}$.

Calcularam-se os valores médios das simulações para os períodos amostrais e compararam-se essas médias aos valores obtidos a partir dos ensaios hidrodinâmicos.

\section{Resultados}

\section{Batimetria}

A batimetria realizada na lagoa facultativa permitiu identificar a existência de um fundo da lagoa irregular, com profundidades variando entre 1,60 e 2,10 m, não sendo identificadas alturas significativas do material sedimentado ao longo do fundo da lagoa.

A Tabela 2 contém o volume de lodo calculado a partir das batimetrias realizadas, assim como o percentual de lodo em relação ao volume total das lagoas, o volume líquido e a profundidade média obtida em função das áreas médias das lagoas.

\section{Ensaios hidrodinâmicos}

\section{Primeiro ensaio}

Durante a realização do primeiro ensaio hidrodinâmico na lagoa facultativa, feito no período de 1 a 22 de julho de 2003, a vazão média afluente foi de $180,78 \mathrm{~m}^{3} / \mathrm{h}$. Relacionando a vazão com o volume líquido da lagoa facultativa, calculou-se o TDH teórico como 307,4 horas (12,8 dias).

A Figura 2 apresenta a variação da concentração de Rodamina B observada no efluente em função do tempo decorrido desde o momento de lançamento do traçador.

O TDH real resultou em 172,2 horas (7,2 dias), com número de dispersão (d) igual a 0,405. Ao se relacionar o TDH real com o TDH teórico, observou-se volume ativo de 56,0\%. Neste ensaio, obteve-se $56,6 \%$ de recuperação da massa do traçador, sendo 5,8 horas o tempo médio entre duas coletas. A recuperação de massa neste ensaio foi significativamente menor do que a recomendada, assim, esses resultados devem ser vistos com cautela e este ensaio foi descartado nas análises posteriores.

\section{Segundo ensaio}

Durante a realização do segundo ensaio hidrodinâmico na lagoa facultativa, feito no período de 13 de outubro a 14 de novembro de 2003, a vazão média afluente foi de 194,00 m³/h. Relacionando-se a vazão com o volume líquido da lagoa facultativa, calculou-se o TDH teórico como o 286,5 horas (11,9 dias). Os resultados desse ensaio são mostrados na Figura 3.

O TDH real resultou em 175,9 horas (7,3 dias), com número de dispersão (d) igual a $1,11 \times 10^{7}$. Ao relacionar o TDH real com o TDH 
teórico, observou-se volume ativo de $61,4 \%$. Neste ensaio obtevese $96,3 \%$ de recuperação da massa do traçador, sendo 3,2 horas o tempo médio entre duas coletas. A recuperação de massa neste caso ultrapassou os valores mínimos recomendados para garantir confiabilidade aos resultados.

\section{Terceiro ensaio}

Durante a realização do terceiro ensaio hidrodinâmico, o primeiro realizado na lagoa de maturação em agosto de 2004, a vazão média afluente foi de $176,47 \mathrm{~m}^{3} / \mathrm{h}$. Relacionando a vazão com o volume líquido da lagoa facultativa, calculou-se o TDH teórico como 186,5 horas ( 7,8 dias). O perfil de concentração do traçador neste ensaio é apresentado na Figura 4.

O TDH real resultou em 47,4 horas (2,0 dias), com número de dispersão (d) igual a $1,11 \times 10^{9}$. Ao relacionar o TDH real com o TDH teórico, observou-se volume ativo de 25,4\%. Neste ensaio obteve-se 97,4\% de recuperação da massa do traçador, sendo 2,4 horas o tempo médio entre duas coletas.

\section{Quarto ensaio}

Durante a realização do quarto ensaio hidrodinâmico, o segundo feito na lagoa de maturação, entre 5 e 22 de fevereiro de 2005, a va-

Tabela 2 - Volumes de lodo e líquido das lagoas de estabilização submetidas aos ensaios hidrodinâmicos

\begin{tabular}{|c|c|c|c|c|}
\hline Lagoa & $\begin{array}{l}\text { Volume } \\
\text { de Lodo } \\
\qquad\left(\mathrm{m}^{3}\right)\end{array}$ & $\begin{array}{c}\text { Volume de lodo em relação } \\
\text { ao volume total } \\
(\%)\end{array}$ & $\begin{array}{l}\text { Volume } \\
\text { líquido } \\
\left(\mathrm{m}^{3}\right)\end{array}$ & $\begin{array}{l}\text { Profundidade } \\
\text { média líquida } \\
(\mathrm{m})\end{array}$ \\
\hline Facultativa & 2.961 & 5,06 & 52.572 & 1,70 \\
\hline Maturação & 317 & 0,98 & 32.917 & 1,80 \\
\hline
\end{tabular}

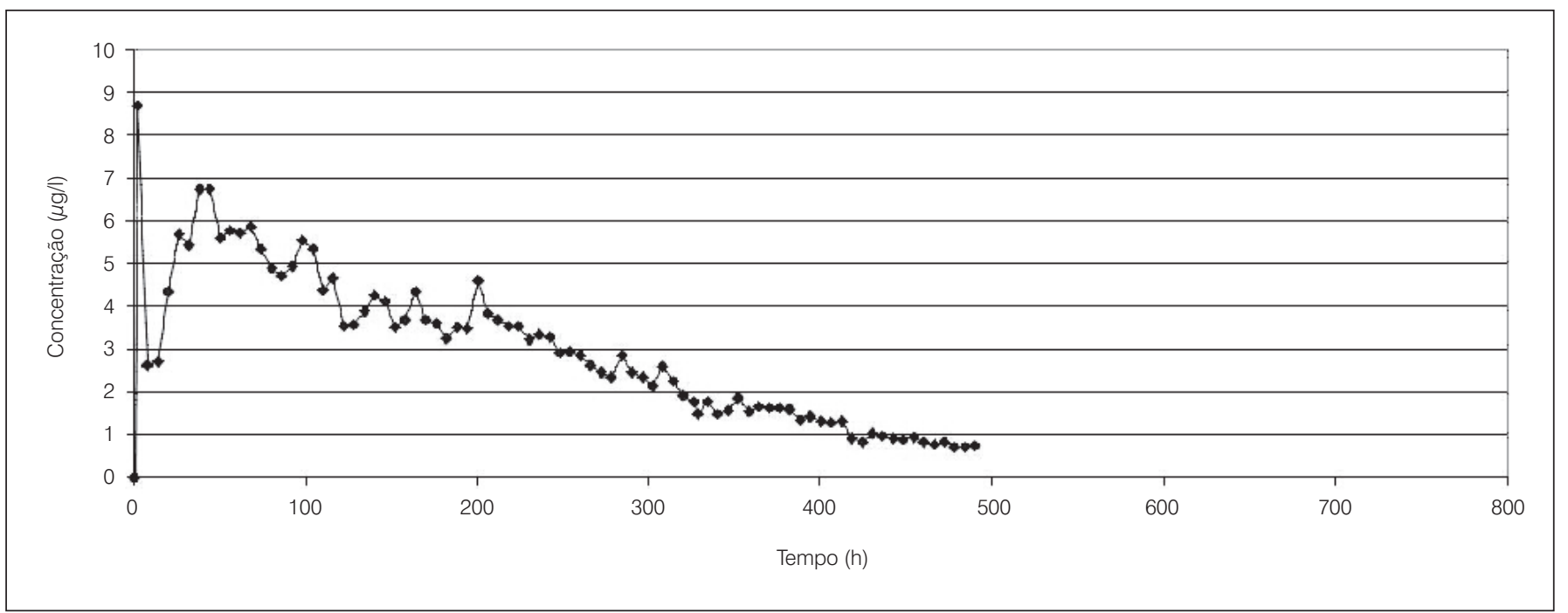

Figura 2 - Curva de saída da concentração de Rodamina B em função do tempo, lagoa facultativa, julho de 2003

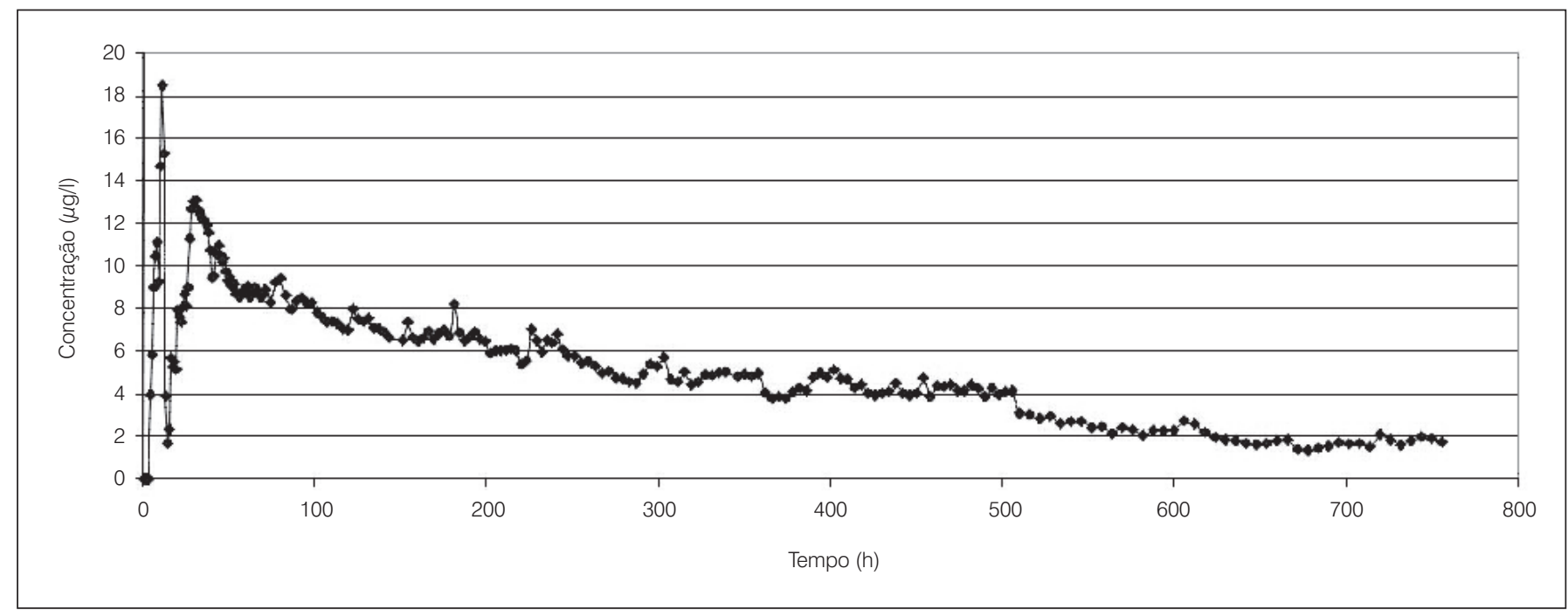

Figura 3 - Curva de saída da concentração de Rodamina B em função do tempo, lagoa facultativa, novembro de 2003 


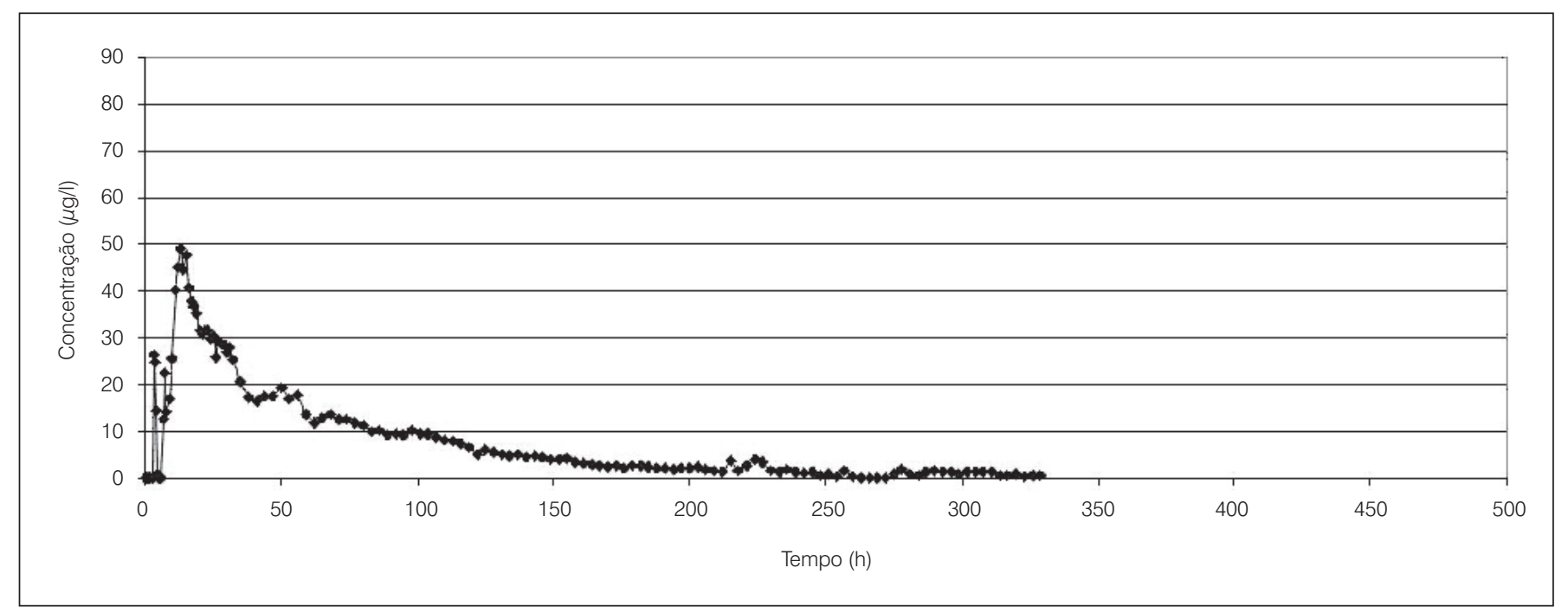

Figura 4 - Curva de saída da concentração de Rodamina B em função do tempo, lagoa de maturação, agosto de 2004

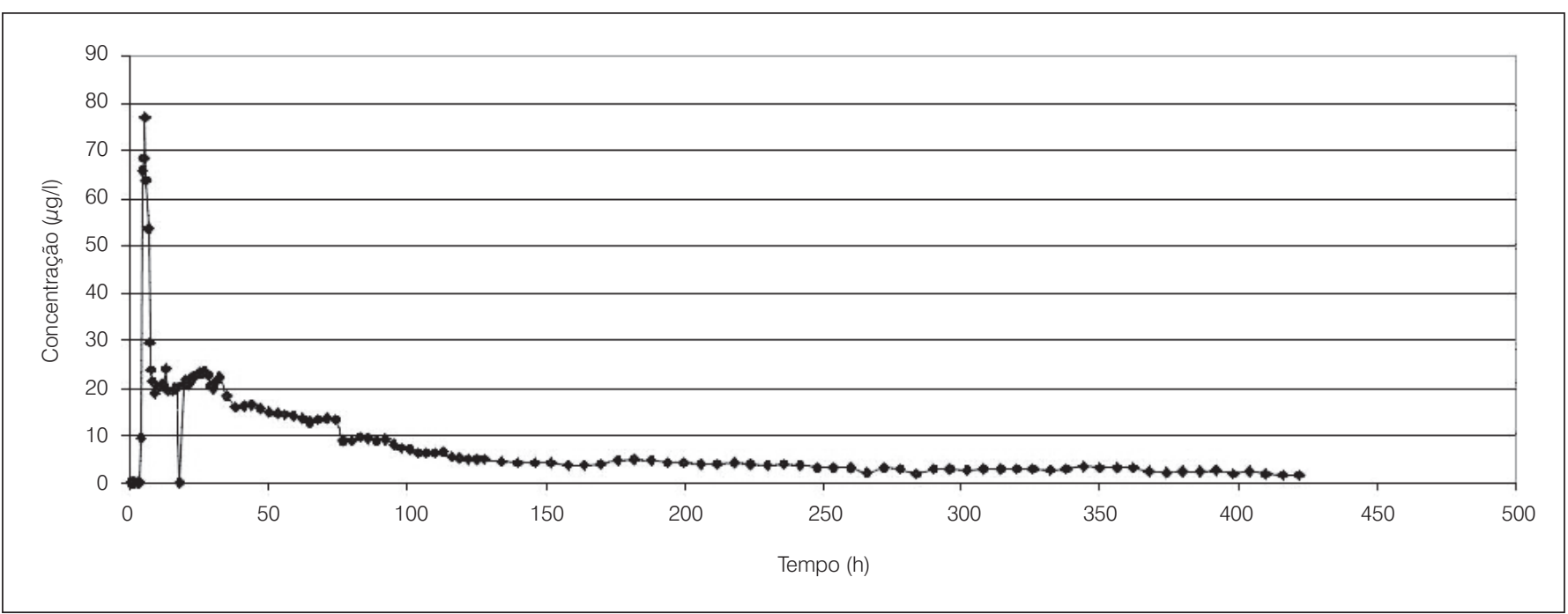

Figura 5 - Curva de saída da concentração de Rodamina B em função do tempo, lagoa de maturação, março de 2005

zão média afluente foi de $200,65 \mathrm{~m}^{3} / \mathrm{h}$, que fornece um TDH teórico de 164,1 horas (6,8 dias). Este ensaio está representado na Figura 5.

O TDH real resultou em 55,1 horas (2,3 dias), com número de dispersão (d) igual a $1,10 \times 10^{9}$. Ao relacionar o TDH real com o TDH teórico, observou-se volume ativo de 33,6\%. Neste ensaio obteve-se 95,6\% de recuperação da massa do traçador, sendo 3,5 horas o tempo médio entre duas coletas.

A Tabela 3 apresenta os resultados referentes à porcentagem de recuperação da massa do traçador, tempo médio entre duas coletas consecutivas, relação entre o tempo de duração da campanha de amostragem e TDH para os quatro ensaios realizados.

A Tabela 4 apresenta os principais resultados obtidos para os ensaios hidrodinâmicos considerados válidos do ponto de vista amostral.

\section{Distribuição da concentração de Rodamina B ao longo da profundidade da lagoa facultativa}

A Figura 6 apresenta uma série de gráficos compostos, contendo a variação da concentração de Rodamina B e da temperatura do líquido ao longo da profundidade da lagoa facultativa, durante o segundo ensaio hidrodinâmico.

\section{Simulação numérica do volume útil das lagoas}

A Tabela 5 apresenta os resultados obtidos a partir da simulação numérica feita para as lagoas facultativa e de maturação da ETE de Novo Horizonte, segundo o modelo matemático proposto por Kellner (2000). 
Tabela 3 - Comparação entre o percentual de recuperação da massa do traçador e o tempo médio entre duas amostragens consecutivas

\begin{tabular}{lcccc} 
Lagoa & Ensaio & $\begin{array}{c}\text { Recuperação } \\
\text { da massa do } \\
\text { traçador } \\
\text { (\%) }\end{array}$ & $\begin{array}{c}\text { Tempo } \\
\text { médio } \\
\text { entre duas } \\
\text { amostragens } \\
\text { consecutivas } \\
\text { (h) }\end{array}$ & $\begin{array}{c}\text { Relação do tempo } \\
\text { de duração da } \\
\text { campanha de } \\
\text { amostragem com } \\
\text { o TDH teórico } \\
\text { da lagoa } \\
\text { (adimensional) }\end{array}$ \\
\hline Facultativa & I & 56,5 & 5,8 & 1,59 \\
& II & 96,3 & 3,2 & 2,64 \\
Maturação & III & 97,4 & 2,4 & 1,76 \\
& IV & 95,6 & 3,5 & 2,26
\end{tabular}

Tabela 4 - Características gerais dos ensaios hidrodinâmicos

\begin{tabular}{lccc} 
& \multicolumn{3}{c}{ Ensaios } \\
\cline { 2 - 4 } Características & II (a) & III(b) & IV(b) $^{(\mathrm{b}}$ \\
\hline Período & Out./nov. & Ago. & Fev. \\
Volume ativo (\%) & 61,4 & 25,4 & 33,6 \\
\hline $\begin{array}{l}\text { Volume morto (\%) } \\
\text { Tempo de detenção } \\
\text { hidráulico teórico (horas) }\end{array}$ & 38,6 & 74,6 & 66,4 \\
$\begin{array}{l}\text { Tempo de detenção } \\
\text { hidráulico real (horas) }\end{array}$ & 175,9 & 47,4 & 55,1 \\
\hline Número de dispersão (adimensional) & $\rightarrow \infty$ & $\rightarrow \infty$ & $\rightarrow \infty$
\end{tabular}

(a) ensaio hidrodinâmico conduzido na lagoa facultativa; (b) ensaio hidrodinâmico conduzido na lagoa de maturação.

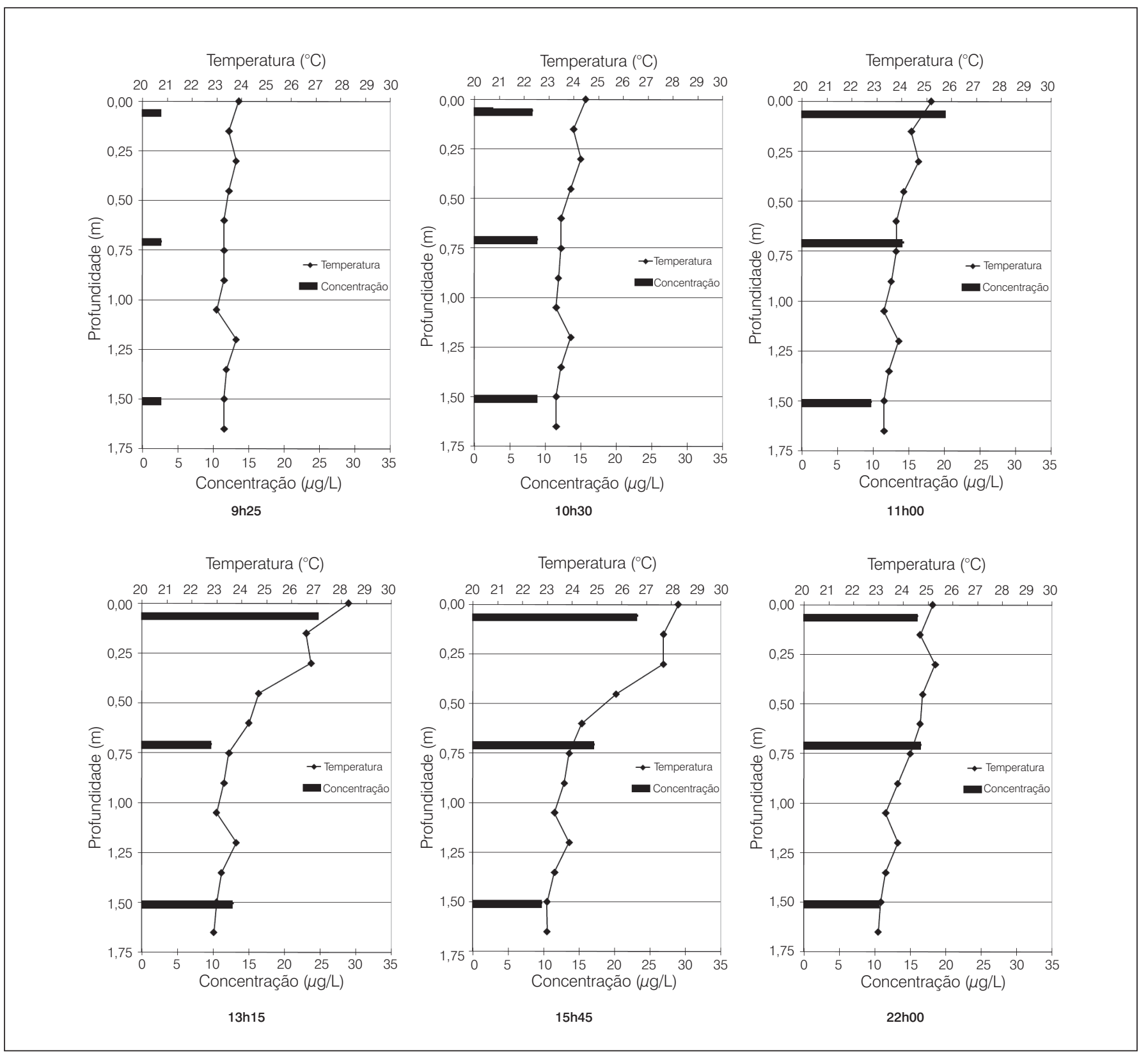

Figura 6 - Variação nictimeral da distribuição vertical da concentração de Rodamina B e da temperatura do líquido na lagoa facultativa no segundo ensaio hidrodinâmico, 13 de novembro de 2003 
Tabela 5 - Resultados obtidos a partir da Simulação Numérica para estimação do volume útil das lagoas de estabilização segundo o modelo proposto por Kellner (2000)

\begin{tabular}{|c|c|c|c|}
\hline Lagoa & Ensaio & $\begin{array}{l}\text { Período utilizado } \\
\text { para simulação } \\
\text { numérica }\end{array}$ & $\begin{array}{l}\text { Volume útil } \\
\text { estimado } \\
\text { (\%) }\end{array}$ \\
\hline \multirow[b]{2}{*}{ Facultativa } & I & $\begin{array}{l}10 \text { a } 22 \text { de julho } \\
\text { de } 2003\end{array}$ & $60,9 \pm 2,1$ \\
\hline & II & $\begin{array}{c}13 \text { de outubro a } \\
14 \text { de novembro } \\
\text { de } 2003\end{array}$ & $62,1 \pm 0,1$ \\
\hline \multirow[t]{2}{*}{ Maturação } & III & $\begin{array}{l}28 \text { de agosto a } \\
7 \text { de setembro } \\
\text { de } 2004\end{array}$ & $30,1 \pm 5,7$ \\
\hline & IV & $\begin{array}{c}2 \text { a } 22 \text { de fevereiro } \\
\text { de } 2005\end{array}$ & $33,8 \pm 0,1$ \\
\hline
\end{tabular}

A Tabela 6 apresenta os resultados obtidos para o volume útil das lagoas de estabilização durante os ensaios realizados e aqueles obtidos segundo o modelo proposto por Kellner (2000).

\section{Discussão}

\section{Batimetria}

A partir das batimetrias realizadas nas lagoas facultativa e de maturação, calculou-se o volume de lodo depositado no fundo das lagoas, bem como a porcentagem desse volume em relação ao volume total das lagoas, conforme apresentado na Tabela 2.

A lagoa facultativa apresentou o maior volume de lodo acumulado, representando 5,06\% do volume total da lagoa; a lagoa de maturação, por sua vez, apresentou uma quantidade menor de lodo sedimentado, o que representou $0,96 \%$ do volume total.

Se fosse considerado o volume de lodo igualmente distribuído nas lagoas e, considerando o início de operação da ETE, as taxas volumétricas de acúmulo de lodo da ordem de 670,42 m³/ano e 71,77 m³/ano teriam sido obtidas para as lagoas facultativa e de maturação, respectivamente. No entanto, se considerada a área superficial média de cada lagoa, as taxas de acúmulo de lodo seriam da ordem de 2,05 cm/ano e 0,39 cm/ ano, para as lagoas facultativa e de maturação, respectivamente.

Segundo levantamento coordenado por Gonçalves (2000), em várias lagoas de estabilização, nas lagoas facultativas primárias, a taxa linear de acúmulo de lodo tende a 2,0 cm/ano e, para as lagoas facultativas secundárias, quando corretamente dimensionadas, o acúmulo de lodo é praticamente desprezível.

Com relação do TDH teórico, o volume de lodo depositado nas lagoas proporcionou variações da ordem de 5,06 e 0,96\%, valores esses que podem ser considerados desprezíveis

\section{Ensaios hidrodinâmicos}

A partir do ponto de vista de validação do experimento e observando-se as porcentagens de recuperação da massa do traçador
Tabela 6 - Comparação entre os volumes úteis observados nos ensaios hidrodinâmicos validados com os estimados teoricamente pelo modelo de estratificação térmica

\begin{tabular}{lccc|} 
& \multicolumn{3}{c}{ Ensaio } \\
\cline { 2 - 4 } Característica & II (a) & III(b) & IV(b) $^{(\text {b) }}$ \\
\hline Volume útil observado (\%) & 61,4 & 25,4 & 33,6 \\
\hline Volume útil estimado (\%) & $62,1 \pm 0,1$ & $30,1 \pm 5,7$ & $33,8 \pm 0,1$
\end{tabular}

(a) ensaio hidrodinâmico conduzido na lagoa facultativa; (b) ensaio hidrodinâmico conduzido na lagoa de maturação.

apresentados na Tabela 3, o primeiro ensaio hidrodinâmico teve de ser descartado, pois a recuperação da massa de Rodamina B utilizada como traçador foi de 56,6\% em relação à massa introduzida.

Segundo Dorego e Leduc (1996), o período de coleta deve ser no mínimo duas vezes o TDH teórico. Para Simi e Mitchell (1999), em seus estudos sobre lagoas de estabilização de efluentes em refinaria de petróleo, o período de coleta de amostras deve ser de três vezes o TDH, valor esse também relatado por Kellner e Pires (1998). Shilton (2005) sugere que o tempo mínimo de amostragem seja de cinco vezes o TDH teórico da lagoa.

Embora o método de coleta utilizado nesse primeiro ensaio tenha diferido do método empregado nos outros ensaios hidrodinâmicos, e o tempo de coleta tenha se estendido por 1,59 vezes o TDH da lagoa, infere-se que esse baixo índice de recuperação do traçador esteja relacionado ao tempo médio transcorrido entre duas coletas consecutivas de amostras que, no caso do primeiro ensaio foi de 5,8 horas. A Tabela 3 ilustra essa hipótese.

Ao observar os dados apresentados na Tabela 4, percebe-se que em todos os ensaios hidrodinâmicos conduzidos, o TDH real foi sempre inferior ao TDH teórico, indicando, portanto, a existência de zonas mortas. Na lagoa facultativa, o volume ativo foi da ordem de $61,4 \%$ para o período de outubro a novembro de 2003; já o volume ativo da lagoa de maturação variou de 25,4 a 33,6\% para os períodos de agosto de 2004 a fevereiro de 2005.

Nos três ensaios analisados, o número de dispersão calculado foi alto, podendo se considerar que houve tendência ao infinito, característica essa intrínseca aos reatores de mistura completa. No entanto, Arceivala (1983) observou que em algumas lagoas de estabilização, principalmente naquelas localizadas em pontos de clima quente, embora os números de dispersão atingissem valores superiores a 4,0, o meio líquido não estava completamente misturado, estando as lagoas estratificadas termicamente. Thackston, Shields Junior e Schroeder (1987) observam que o número de dispersão e o TDH médio são completamente independentes entre si.

Torres, Soler e Ortuno (1997) e Torres et al (2000) relataram os experimentos feitos em uma lagoa facultativa na Espanha utilizando a sulforodamina B como traçador. Os pesquisadores verificaram que o TDH real foi de até 1/5 o TDH teórico, estando o volume ativo comportando-se hidraulicamente como um reator de mistura completa.

Analisando as Figuras 3, 4, 5 e 6 que representam, respectivamente, as curvas de saída das concentrações de Rodamina B em função do tempo nas lagoas analisadas, nos ensaios I, II, III e IV, é 
possível observar a ocorrência de um comportamento hidrodinâmico irregular nas primeiras 25 horas dos experimentos, com alguns picos de concentração do traçador observados no efluente, para então seguir um padrão regular esperado, com a diminuição da concentração do traçador no efluente ao longo do tempo.

Essa irregularidade hidrodinâmica é característica de curtocircuitos, que puderam ser observados não só analiticamente, mas visualmente, já que ao se introduzir o traçador nas lagoas, observouse a mancha avermelhada dirigindo-se rapidamente pela superfície líquida para os dispositivos de saída.

Provavelmente, a massa de traçador, misturada às camadas superficiais do epilíminio, somente misturou-se às camadas mais profundas após a ocorrência da desestratificação térmica quando, então, o comportamento hidrodinâmico passou a seguir um padrão esperado.

Analisando-se os perfis de temperatura obtidos para os três ensaios validados, observou-se a ocorrência de estratificação térmica não duradoura nas lagoas facultativa e de maturação, com homogeneização térmica nos períodos noturnos (sem insolação).

Analisando-se a Figura 6, percebe-se que, com a estratificação térmica do meio líquido, ocorreu significativa variação na distribuição vertical da concentração da Rodamina B. Com o aquecimento das camadas líquidas mais profundas, ocorreria a formação de correntes de densidade que transportariam a massa do traçador para as camadas superiores, aumentando, assim, sua concentração. Ao ocorrer o resfriamento das camadas superiores e, consequentemente, o aumento da densidade do líquido, essa corrente de densidade se inverteria, transportando a massa do traçador para as camadas inferiores e aumentando sua concentração, igualando-se à concentração observada nas camadas mais superficiais.

Para o modelo computacional utilizado, adotou-se como critério para estimação do volume útil o do gradiente automático. Segundo Kellner (2000), esse critério parte da hipótese de que o meio líquido estratifica-se a partir da ocorrência da variação da densidade da água em $8 \mathrm{~g} / \mathrm{m}^{3} / \mathrm{m}$, proporcionada pela diferença da temperatura entre duas camadas líquidas, valor esse originado a partir da diferença de densidade da água para temperatura entre $4^{\circ} \mathrm{C}$ e $5^{\circ} \mathrm{C}$, usados como referência para definição da estratificação térmica de $1^{\circ} \mathrm{C} / \mathrm{m}$.

Kellner e Pires (2002) já haviam relatado que, para lagoas de estabilização que apresentassem temperatura do líquido entre $24^{\circ} \mathrm{Ce} 25^{\circ} \mathrm{C}$, o gradiente térmico característico para ocorrência de estratificação térmica seria $0,6^{\circ} \mathrm{C} / \mathrm{m}$. No entanto, com a aplicação do critério do gradiente automático, infere-se que para lagoas com temperaturas superiores a $25^{\circ} \mathrm{C}$, esse gradiente térmico pode ser ainda menor, o que torna esse fenômeno mais significativo para as lagoas de estabilização construídas em clima tropical.
A aplicação do modelo matemático proposto por Kellner (2000) para a estimativa do volume útil da lagoa facultativa indicou que esse volume variou $62,1 \pm 0,1 \%$ para o período de 13 de outubro a 14 de novembro de 2003, enquanto na lagoa de maturação essa variação foi de $30,1 \pm 5,7 \%$ para o período de 28 de agosto a 7 setembro de 2004 e 33,8 \pm 0,1\% para o período de 2 a 22 de fevereiro de 2005 , conforme observado na Tabela 5.

A aplicação do modelo matemático proposto por Kellner (2000) para estimativa dos perfis de temperatura e do volume útil para lagoas de estabilização apresentou bons resultados quando comparados aos volumes ativos observados experimentalmente, como se pode visualizar na Tabela 6.

\section{Conclusões}

Com base nos resultados obtidos neste trabalho, concluiu-se que:

i) o acúmulo de lodo na lagoa facultativa foi da ordem de $2,05 \mathrm{~cm} /$ ano e desprezível na lagoa de maturação;

ii) a estratificação térmica nas lagoas da ETE de Novo Horizonte não foi estável, ocorrendo períodos de mistura, principalmente durante a noite, o que proporcionou a homogeneização térmica das lagoas;

iii) a estratificação térmica influenciou o transporte do traçador no interior da lagoa, formando camadas com diferentes concentrações de Rodamina B ao longo da profundidade;

iv) nos três ensaios hidrodinâmicos validados, embora os tempos de detenção hidráulico real tenham sido menores que os tempos de detenção hidráulica teórico, os números de dispersão calculados, bem como as curvas de saída, mostram características de reatores de mistura completa;

v) o modelo matemático empregado para estimação do volume útil das lagoas de estabilização apresentou boa resposta ao se compararem seus resultados àqueles obtidos por ensaio de campo, empregando-se como traçador a Rodamina B;

vi) para regiões de clima tropical, com temperaturas da água superiores a $25^{\circ} \mathrm{C}$, pode ocorrer estratificação térmica com gradientes de temperatura inferiores a $0,6^{\circ} \mathrm{C} / \mathrm{m}$.

\section{Agradecimentos}

Os autores agradecem à Sabesp pelo apoio dado no decorrer do levantamento experimental. Agradecem, ainda, à Fundação de Amparo à Pesquisa do Estado de São Paulo (Fapesp) pelo financiamento deste trabalho, à Coordenação de Aperfeiçoamento de Pessoal de Nível Superior (Capes) pela bolsa de doutorado do Engenheiro João Fernandes Viana Moreira, ao CNPq pelas bolsas dos professores Erich Kellner (pós-doutorado) e Eduardo Cleto Pires (Produtividade em Pesquisa, 1B) 


\section{Referências}

ARCEIVALA, J.S. Hydraulic modeling for waste stabilization ponds. Journal of Environmental Engineering-ASCE, v. 109, n. 1, p. 265-268, 1983.

CHU, C.R.; SOONG, C.K. Numerical simulation of wind-induced entrainment in a stably stratified water basin. Journal of Hydraulic Research, v. 35, n. 1, p. 21-41, 1997.

COSSIO, F.Y. Lagunas de estabilización: teoria, diseño, evaluación y mantenimiento. Opas/OMS, 1993.

DOREGO, N.C.; LEDUC, R. Characterization of hydraulic flow patterns in facultative aerated lagoons. Water Science and Technology, v. 34, n. 11, p. 99-106, 1996.

ESTEVES, F.A. Fundamentos de limnologia. Rio de Janeiro: Interciência/ Finep, 1998.

GONÇALVES, R.F. (Coord.). Gerenciamento do lodo de lagoas de estabilização não mecanizadas. Rio de Janeiro: ABES, 2000.

KELLNER, E. Modelação matemática do comportamento térmico de lagoas de estabilização: a estratificação e seus efeitos. 136 f. Tese de Doutorado - Escola de Engenharia de São Carlos, USP, São Carlos, 2000.

KELLNER, E.; PIRES, E.C. The influence of thermal stratification on the hydraulic behavior of waste stabilization ponds. Water Science and Technology, v. 45, n. 1, p. 41-48, 2002.

- Lagoas de estabilização: projeto e operação. Rio de Janeiro: ABES, 1998. v. 1
LEVENSPIEL, O. Engenharia das reações químicas: volume 2 - cálculo de reatores. São Paulo: Edgard Blücher Ltda., 1974.

MOREIRA, J.F.V. Subsídios para estudos hidrodinâmicos em sistemas de lagoas de estabilização sob influência de estratificação térmica: estudo de caso no noroeste paulista. Tese de Doutorado - Escola de Engenharia de São Carlos, USP, São Carlos, 2006.

SHILTON, A. (Ed.). Pond treatment technology. London: IWA Publishing, 2005.

SIMI, A.L.; MITCHELL, C.A. Design and hydraulic performance of a constructed wetland treating oil refinery wastewater. Water Science Technology, v. 40. p. 301-307, 1999.

TEIXEIRA, E.C. Importância da hidrodinâmica de reatores na otimização de processos de desinfecção de águas de abastecimento: uma análise crítica. In: $18^{\circ}$ CONGRESSO BRASILEIRO DE ENGENHARIA SANITÁRIA E AMBIENTAL, Anais... Rio de Janeiro: Associação Brasileira de Engenharia Sanitária e Ambiental - ABES, 1995.

THACKSTON, E.L.; SHIELDS JUNIOR, D.; SCHROEDER, P.R. Residence time distributions of shallow basins. Journal of Environmental Engineering, v. 113, n. 6, p. 1319-1332, dez. 1987.

TORRES, J.J. et al. Hydraulic performance of a deep wastewater stabilization pond fed at 3,5m depth. Water Research, v. 34, n. 3. p. 1042 1049,2000

TORRES, J.J.; SOLER, A.J.; ORTUNO, J.F. Hydraulic performance of a deep wastewater stabilization pond. Water Research, v. 31, n. 4. p. 679688,1997 